\title{
The Importance of Sport in Aging Process
}

\author{
Ömer Can Göksu ${ }^{1}$, Selami Yüksek², Vedat Ayan², Mehmet Şirin Güler ${ }^{3}$ \\ ${ }^{1}$ Istanbul University-Cerrahpasa Department of Sport Science Faculty Avc1lar, İstanbul, Turkey \\ ${ }^{2}$ Trabzon University Department of Sport Science Faculty, Turkey \\ ${ }^{3}$ Kafkas University Sarıkamıs School of Physical Education and Sport, Turkey \\ Correspondence: Ömer Can Göksu, Istanbul University-Cerrahpasa Department of Sport Science Faculty Avcılar, \\ İstanbul, Turkey.
}

Received: May 22, 2019

Accepted: June 20, 2019

Online Published: June 26, 2019

doi:10.11114/jets.v7i9.4350

URL: https://doi.org/10.11114/jets.v7i9.4350

\begin{abstract}
The goal of the current study is to investigate the effects of past and current participation in sport and exercise on physical fitness levels of the elderly.

In the current study, the participants were 849 males over the age of 60 who do daily life activities independently and do not have any serious health problems. Participants in the study were divided into 4 groups; those who did sports in their youth and now; (YYOY), those who did sports in their youth, but now don't do it now; (YYON), those who didn't do sports in their youth but now do; (YNOY), and those who have never done any sports; (YNON). A personal information form was used for determine their relationships with sport earlier in life and and now. The protocol of Senior Fitness Test (SFT) consisting of 6 different stations was used to determine of physical fitness levels of participants. The One Way Anova and LSD test was used to analyse variables of differences between groups according to participation in sport early in life and now and the threshold for significance level was 0.05 .

There was statistically significant differences between physical fitness parameters of the groups "those who did sports in their younth, but now don't" (YYON) and "“"Those who didi sports in their youth and now" (YYOY), only. The groups of "those who did sports, but now don't" (YYON) and "have never done sports" (YNON) have the lowest physical fitness levels $(\mathrm{p}<0,05)$.

Physical exercise in terms of sports and exercises have positive effects on physical fitness levels but if the sport is not a life style, physical fitness levels from the exercise will be lost over time. Starting from this point of view, the expression "It doesn't matter what you did yesterday, what you're doing today matters" is extremely important in relation to exercise and sport.
\end{abstract}

Keywords: aging, exercise, detraining, physical fitness

\section{Introduction}

Sport and exercise are a comprehensive phenomenon that concerns all individuals from different age groups for a wide range of purposes such as sociality, health and education all over the world. Sports sport facilities for individuals with physical and mental disabilities are a crucial platform for socialization and mediation. Furthermore, these environments create fun for kids to develop their psychomotor abilities. Sports provide an opportunity to develop survival skills in difficult situations for soldiers and police officers. For the eldery, it should be done to eliminate or at least slow down the symptoms associated with aging. As can be seen, the concept of sport is the common denominator of many factors.

The effect of sports and exercise on human health has been the subject of various studies for many years, and also except in some special circumstances, the concept of "sport is health" has become widespread. So people have been directed to sporting activities. When considering the effects of aging, more careful steps should be taken. The aging process causes an increase in the amount of fat, a decrease in muscle mass, deterioration in movement skills, and ultimately a decrease in independence. And all of these are natural changes in body composition on an elderly person. This situation also brings with it unwanted negativity such as insomnia, depression, fatigue and self-efficacy (Brady, Straight\&Evans, 2014). One of the biggest problems encountered in the elderly population is undoubtedly failure. The deterioration of balance due to aging causes serious crises physically and emotionally (Gobbo et.al ., 2014). It can also 
be evaluated within the symptoms of geriatric syndromes such as decreased movement and muscle mass, time dependent abnormal changes in body mass index, continuous fatigue, and falls and other physical-physiological problems, sarcopenia due to aging (Santilli, Bernetti, Mangone \& Paoloni, 2014; Kim et.al , 2015).

Furthermore, research on sarcopenia shows that regular physical activity is an effective rehabilitation tool that slows, delays and even prevents physical, physiological and mental problems caused by aging. Mijnarends(2016) reported that submaximal physical activities which are done for more than 1 hour over a week slow the formation of sarcopenia between physical activity level and sarcopenia formation in the elderly. Jeon at all (2018) in their study with 76 female participants aged 60 years and over, reported that lower-upper extremity strength values and lung functions of the sarcopenic elderly were improved with regular exercises performed 3 days a week for 30 minutes. Jeoung and Lee (2015), in their research with 114 women in the 65-80 age range, reported that there is a significant negative correlation between physiological fragility and physical performance levels, and the participants with high physical performance levels have low levels of fragility. In a different study, Bullo et al. (2015), as a result of the screening study related to elderly people in the plate exercises; reported that elderly people who have improved strength and walking ability show a better quality of life and mood in daily activities, dynamic and static balance parameter.

Yüksek (2017), in his research with 849 participants aged 60 years and over, found that the levels of motoric performance of individuals who perform islamic prayer rituals were significantly better than those who did not. In a different study investigating the effects of the Plates exercises on the elderly population, Bird and Fell (2014) reported a significant increase in the balance and strength skills of elderly people participating in 12-month plate exercises. Leach and Ruckert (2016), as a result of their scanning research in daily work of elderly people, reported that sporting activities such as cycling, swimming, running and playing tennis play a positive role in parameters such as reaction, attention, coordination and success. Similarly, Hornikova et al.'s study (2018) with a total of 18 participants aged 60 years and over ( 7 of them were table tennis players and 11 of them were the sedentary control group) reported that the quickness scores of the elderly people who were interested in table tennis were higher than in the sedantary control group. The studies support that sport is the only drug without side effects. In order to increase the quality of life in the elderly, it is seen that increasing physical exercises stand out as an effective tool. However, the existence of some questions that need to be considered in this subject makes it necessary to carry out further research in different dimensions. Can a person who is engaged in sports in his youth enjoy a healthy old age? Or, if someone who has spent his youth in sedentary activities starts to exercise regularly when he/she gets older, how efficient is it? Is it more useful to participate in sport at a young age or in old age? These kind of questions are important in terms of planning physical activities for a healthy old age. Therefore, this study was carried out to investigate the effects of current and past participating in sports and exercise on the physical fitness levels of elderly people.

\section{Materials and Methods}

This study was carried out with the voluntary participation of 849 men aged 60 or over who were able to independently conduct their normal daily activities and who did not have any serious health problems. All participants provided written consent in accordance with the Helsinki declaration of 1964, after reading the verbal and written explanations of the potential risks of the study. The participants were informed about the procedure of the experiment and were told that they could voluntarily withdraw from the experiment at any given time. Certain demographic information was obtained about the participants via a questionnaire, including whether they do exercise. Participants in the study were divided into 4 groups those who did sports in their youth and now; (YYOY), those who did sports in their youth, but now don't do it now; (YYON), those who didn't do sports in their youth but now do; (YNOY), and those who have never done any sports; (YNON). Personal information form was used to determine the relationships people between who started sports early in life and started sports late of life. Subjects who had orthopedic or mental disabilities or neurologic or advanced cardiovascular chronic illnesses that might impair or limit test protocols were not included in the study. In performing the physical fitness tests, any clothing that could impede or limit movements, or items like jackets or coats were removed. An experienced assistant was employed for each station and for each participant. Any subjects who were unable to complete any of the stations included in the test protocol were excluded from the evaluation. The distribution of the 849 participants who were found to be suitable for the test criteria and successfully completed the tests are evaluated.

\subsection{Applied Tests}

The six-station Senior Fitness Test (SFT) developed by Rikli and Jones (2001) was applied in order to determine the physical fitness levels of participants. The subjects were put through a 4-5 minute warm-up period (walking, jog-trot, and stretching exercises) before the testing protocol was carried out. The stations constituting test protocol included:

1. Chair Stand Test (30CST): This test was performed in order to determine the lower extremity strengths of subjects. The subject sat upright, feet on the floor and arms crossed over his chest (right hand on left shoulder, left hand on right 
shoulder) in the centre of a $43.18 \mathrm{~cm}$ chair. The test was demonstrated and explained to the subject. After having him perform some trials to make sure that he understood the test correctly, a start command was given, and the subject performed compete rising as often as he could in 30 seconds. The number of complete risings the subject could manage in 30 seconds was recorded as his 30CST score (Rikli \& Jones, 2001).

2. Arm Curl Test (ARCLT): This test was applied in order to determine upper extremity strength. The subject sat on his dominant arm side of the chair. The subject completed the test by lifting the $3.63 \mathrm{~kg}$ dumbbell to complete extension to the floor and to complete flexion upward with his dominant hand for 30 seconds. The number of full lifts he managed in 30 seconds was recorded as his ARCLT score (Rikli\&Jones, 2001).

3. Two Minute Step Test (2MST): This test was applied in order to determine the aerobic endurance of the subjects. While the subject was standing straight, the distance between his front iliac crest and midpoint of his patella was measured. The distance between the midpoint of this distance and the floor was measured, and his step height was determined. In order to determine whether his step height could reach the desired level (the height of his knees), a tape was set up at the subject's knee level. The subject was asked to step barefoot on the same spot and reach the determined height on a $1.5 \times 1.5$ mat for 2 minutes. The subject was asked to start the test with his right foot, making his steps as fast as possible without running. If any step (right or left) did not reach the determined height, those steps were declared null. At the end of two minutes, the number of right foot steps that reached the determined height was recorded as the 2MST score of the participant (Rikli\&Jones, 2001).

4. 8 Foot Up-\&-Go Test (8FUAGT): This test was applied in order to determine the dynamic balance and agility of the subjects. The subject sat leaning back, feet on the floor with both arms on his lap, in the centre of a $43.18 \mathrm{~cm}$ chair. The subject was asked to get up from the chair and turn around a cone placed at a distance of $2.44 \mathrm{~m}$ and return to sit on the chair as quickly as he could. The subject was prompted with a start command, and when he had turned the funnel and sat back down on the chair, the timer was stopped and the time he took to perform the task was recorded in seconds. Each subject performed the test twice, and the best trial was recorded as the test score (Rikli \& Jones, 2001).

5. Chair Sit and Reach Test (CSRT): This test was applied to determine the flexibility of the hamstring muscle group. The subject sat on the point where his thighbone and haunch bone met on the edge of the $43.18 \mathrm{~cm}$ chair, with one of his feet (right or left) flexed at 90 degrees and his sole pressing the floor; his other foot at full extension and his heel pressing the floor. The subject was asked to lean forward toward his toes with his hands, both hands at pronation, one on the top of other and his middle fingers in a line, not bending his knee. If the subject's fingertips did not touch his toes, the distance between them was recorded (-); if they did touch (0), and if they passed his toes (+), the distance was recorded in centimeters. Both legs of the subject were tested, and the best evaluation was recorded as the test score (Rikli \& Jones, 2001).

6. Back Scratch Test (BST): This test was applied in order to determine the upper extremity flexibility, and in particular the shoulder flexibility of the subjects. Each subject stood in an anatomic standing position and was asked to reach the lowest point on his back with one of his arms over his shoulder, his palm facing his back and his fingers at extension. With his other arm, he was asked to reach the highest point on his back, with his palm facing the opposite way and his fingers at extension, and place the fingers of both hands as close together as possible. The distance between his fingertips was recorded. If the middle fingers did not touch, the distance was recorded as (-) centimeters, if the middle fingers touched end to end, the distance was recorded as zero (0), and if one of the middle fingers passed the surface of the other middle finger, the distance was recorded as $(+)$ centimeters. Both of his arms (right arm upper, left arm lower and right arm lower, left arm upper) were measured with this method, and his best evaluation was recorded as the score of this test (Rikli \& Jones, 2001).

\subsection{Statistical Analysis}

The statistical analysis of the data was performed using the "SPSS 11.00 for Windows" package program. The education level of the participants and the frequency and percentage distributions of the participants which were grouped according to their levels of sporting in their youth and old ages were calculated. All groups were found to have normal distribution as a result of analyzing the distribution of the data by using the 'One-Simple Kolmogorov Smirnov' test. Significance levels of the differences between the test performances of the groups were examined in One Way Anova. Any differences between the groups were also examined by using the LSD test at the level of 0.05 and 0.01 . 


\section{Findings}

Table 1. Findings of participants' occupational and educational status, frequencies and percentages of income level

\begin{tabular}{|c|c|c|c|c|c|c|c|c|}
\hline Occupation & $\mathbf{N}$ & $\%$ & Education & $\mathbf{n}$ & $\%$ & Level of Income & $\mathbf{n}$ & $\%$ \\
\hline Civil Servent & 133 & 15,7 & No & 133 & 15,7 & Low & 58 & 6,8 \\
\hline Worker & 204 & 24,0 & Literate & 109 & 12,8 & Medium & 524 & 61,7 \\
\hline Teacher & 23 & 2,7 & Primary School & 421 & 49,6 & High & 246 & 29,0 \\
\hline Police-Warden & 11 & 1,3 & Secondary School & 69 & 8,1 & Very high & 21 & 2,5 \\
\hline Farmer & 213 & 25,1 & High School & 70 & 8,2 & Total & 849 & 100,0 \\
\hline $\begin{array}{l}\text { Lawyer-Attorne } \\
\text { y-Judge }\end{array}$ & 4 & 0,5 & University & 47 & 5,5 & & & \\
\hline Doctor-Nurse & 2 & 0,2 & Total & 849 & 100,0 & & & \\
\hline Unemployed & 16 & 1,9 & & & & & & \\
\hline $\begin{array}{l}\text { Self-employed- } \\
\text { Tradesmen }\end{array}$ & 192 & 22,6 & & & & & & \\
\hline Driver & 33 & 3,9 & & & & & & \\
\hline Soldier & 10 & 1,2 & & & & & & \\
\hline Other & 8 & 0,9 & & & & & & \\
\hline Total & 849 & 100,0 & & & & & & \\
\hline
\end{tabular}

In the statistical evaluation, the frequency and percentage of the information of occupational, education and income level of the participants were determined.

Table 2. Finding on the level of sport done by the participants and on the sporting situations of the participants in their youth and now

\begin{tabular}{l|c|c|l|c|c|l|c|c}
\hline \multirow{2}{*}{} & \multicolumn{2}{|c|}{ DidYou Any Sport in YourYouth? } & \multicolumn{3}{c|}{ What Level Did You Do Sport? } & \multicolumn{3}{c}{ Do You Sport Currently? } \\
\cline { 2 - 8 } & $\mathrm{N}$ & $\%$ & & $\mathrm{n}$ & $\%$ & & $\mathrm{n}$ & $\%$ \\
\hline Yes & 247 & 29,1 & Amateur & 227 & 26,7 & Yes & 150 & 17,7 \\
\hline No & 602 & 70,9 & Professional & 20 & 2,4 & No & 699 & 82,3 \\
\hline Total & 849 & 100,0 & Total & 849 & 100,0 & Total & 849 & 100,0 \\
\hline
\end{tabular}

In the statistical evaluation, the frequency and percentages of the participants sporting conditions regarding whether they did sport during their youth period, the level of sports they did as amateur or professional and whether they do now were determined.

Table 3. Findings of the participants on which sports they did in their youth, what sports they do now and why they did not do sports

\begin{tabular}{|c|c|c|c|c|c|c|c|c|}
\hline \multicolumn{3}{|c|}{ Which Sport Did You Do Past? } & \multicolumn{3}{|c|}{\begin{tabular}{|l|} 
Which Sport Do You Do Currently? \\
\end{tabular}} & \multicolumn{3}{|c|}{ Why Don't You Do Sport? } \\
\hline Sports Branch & $\mathbf{n}$ & $\%$ & Sports Branch & $\mathbf{n}$ & $\%$ & & n & $\%$ \\
\hline Football & 122 & 14,4 & Walking & 145 & 17,1 & Unnecessary & 118 & 13,9 \\
\hline Basketball & 7 & 0,8 & Jogging & 3 & 0,4 & I do not have time & 81 & 9,5 \\
\hline Athletics & 43 & 5,1 & Swimming & 2 & ,2 & Aging & 273 & 32,2 \\
\hline Fighting Sports & 40 & 4,7 & Total & 150 & 17,7 & Funny and Ridiculous & 27 & 3,2 \\
\hline Swimming & 7 & 0,8 & & & & Disease & 89 & 10,5 \\
\hline Volleyball & 28 & 3,3 & & & & Don't know/ No reason & 71 & 8,4 \\
\hline $\begin{array}{l}\text { Didn't do any } \\
\text { sport }\end{array}$ & 602 & 70,9 & Don't do any sport & 699 & 82,3 & Other & 40 & 4,7 \\
\hline Total & 849 & 100,0 & Total & 849 & 100,0 & Total & 699 & 82,3 \\
\hline
\end{tabular}

In the statistical evaluation, the frequency and percentages of the sports branches which the participants did in their youth period and they are interested in now were determined. Also, if they do not do any exercise, the frequency and percentages of the reasons for this were determined. 
Table 4. Senior Fitness Test Scores According to Participant's Sporting Status

\begin{tabular}{|c|c|c|c|c|c|c|c|c|c|c|}
\hline \multicolumn{2}{|c|}{$\begin{array}{c}\text { Past And Present Sports } \\
\text { Status }\end{array}$} & $\begin{array}{l}\text { Age } \\
\text { (year) }\end{array}$ & $\begin{array}{c}\text { Heigth } \\
(\mathrm{cm})\end{array}$ & $\begin{array}{l}\text { Weigth } \\
(\mathrm{kg})\end{array}$ & $\begin{array}{l}\text { Chir } \\
\text { Stand } \\
\text { Test } \\
\text { (reps) }\end{array}$ & $\begin{array}{c}\text { Arm-Curl } \\
\text { Test } \\
\text { (reps) }\end{array}$ & $\begin{array}{c}\text { Two } \\
\text { Minute } \\
\text { Step } \\
\text { Test } \\
\text { (Steps) } \\
\end{array}$ & $\begin{array}{l}\text { Chair } \\
\text { Sit } \\
\text { \&Reach } \\
\text { Test } \\
\text { (cm) }\end{array}$ & $\begin{array}{c}\text { Back } \\
\text { Scratch } \\
\text { Test } \\
(\mathrm{cm})\end{array}$ & $\begin{array}{c}8 \\
\text { FootUp-\& } \\
\text { Go Test } \\
\text { (seconds) }\end{array}$ \\
\hline \multirow{4}{*}{$\begin{array}{c}\text { This who did } \\
\text { sports both now } \\
\text { and in their youth } \\
\text { n:63 } \\
\text { (YYOY) } \\
\% \text { of Total N:7,4\% }\end{array}$} & $\mathrm{X}$ & 67,4 & 171,8 & 78,0 & 16,6 & 18,0 & 80,9 & $-1,6$ & $-3,7$ & 4,9 \\
\hline & $\pm \mathrm{SD}$ & 6,3 & 6,3 & 9,1 & 3,1 & 2,4 & 16,2 & 9,1 & 8,7 & 1,2 \\
\hline & Min. & 60 & 160 & 61 & 11 & 12 & 30 & -30 & -26 & 3,5 \\
\hline & Max. & 85 & 197 & 97 & 24 & 23 & 118 & 12,5 & 10,5 & 9,1 \\
\hline \multirow{4}{*}{$\begin{array}{l}\text { Those who did } \\
\text { sport in their youth } \\
\text { but not now } \\
\text { (YYON) } \\
\text { N:184 } \\
\% \text { of Total N: } \\
21,7 \%\end{array}$} & $\mathrm{X}$ & 67,2 & 171,4 & 78,4 & 15,0 & 16,7 & 67,7 & $-4,9$ & $-8,1$ & 5,3 \\
\hline & $\pm \mathrm{SD}$ & 5,7 & 6,53 & 11,03 & 3,1 & 3,0 & 16,1 & 8,7 & 8,9 & 1,2 \\
\hline & Min. & 60 & 157 & 47 & 6 & 7 & 20 & -34 & -32 & 3,5 \\
\hline & Max. & 86 & 190 & 120 & 21 & 24 & 103 & 17,5 & 6 & 13,3 \\
\hline \multirow{4}{*}{$\begin{array}{c}\text { Thos who didn't } \\
\text { do sport in their } \\
\text { youth but do now } \\
\text { (YNOY) } \\
\text { N: } 87 \\
\% \text { of Total N: } \\
10,2 \%\end{array}$} & $\mathrm{X}$ & 67,9 & 170,6 & 79,3 & 15,3 & 17,8 & 80,7 & $-2,1$ & $-8,1$ & 5,0 \\
\hline & $\pm \mathrm{SD}$ & 5,5 & 6,5 & 10,1 & 2,9 & 2,8 & 15,7 & 9,7 & 10,1 & 0,9 \\
\hline & Min. & 60 & 158 & 53 & 11 & 11 & 41 & -28 & -34 & 3,4 \\
\hline & Max. & 90 & 184 & 110 & 22 & 25 & 125 & 17,5 & 8,5 & 8,1 \\
\hline \multirow{4}{*}{$\begin{array}{c}\text { Those who have } \\
\text { never done any } \\
\text { sports } \\
\text { (YNON) } \\
\mathrm{N}: 515 \\
\% \text { of Total N: } \\
60,7 \%\end{array}$} & $\mathrm{X}$ & 69,7 & 167,9 & 75,2 & 13,9 & 15,64 & 62,4 & $-5,3$ & $-11,3$ & 5,8 \\
\hline & $\pm \mathrm{SD}$ & 6,2 & 6,1 & 11,1 & 3,2 & 2,9 & 16,3 & 8,5 & 9,6 & 1,5 \\
\hline & Min. & 60 & 143 & 49 & 5 & 6 & 15 & -36 & -42 & 3,6 \\
\hline & Max. & 92 & 185 & 139 & 24 & 25 & 108 & 11,5 & 8,5 & 16,7 \\
\hline \multirow{4}{*}{$\begin{array}{c}\text { Total } \\
\text { n: } 849 \\
\% \text { of Total N: } \\
100,0 \%\end{array}$} & $\mathrm{X}$ & 68,8 & 169,2 & 76,5 & 14,5 & 16,2 & 66,8 & $-4,6$ & $-9,7$ & 5,6 \\
\hline & $\pm \mathrm{SD}$ & 6,1 & 6,4 & 10,9 & 3,2 & 3,06 & 17,5 & 8,8 & 9,7 & 1,4 \\
\hline & Min. & 60 & 143 & 47 & 5 & 6 & 15 & -36 & $-42,0$ & 3,4 \\
\hline & Max. & 92 & 197 & 139 & 24 & 25 & 125 & 17,5 & 10,5 & 16,7 \\
\hline
\end{tabular}

Physical fitness performance values of the participants according to their sports youth and their level of sports are given in Table 4. 
Table 5. Findings of the differences between the physical conditions of the participants and their sporting conditions according to the results of the motoric test

\begin{tabular}{|c|c|c|c|c|}
\hline PARAMETERS & GROUPS & $\mathbf{X} \pm$ Sd & $\mathbf{p}$ & Difference Group -(p) \\
\hline \multirow{4}{*}{$\begin{array}{l}\text { Age } \\
\text { (year) }\end{array}$} & 1 (YYOY) & $67,4 \pm 6,3$ & \multirow{4}{*}{0,000} & \multirow{4}{*}{$\begin{array}{l}1-4(0,006) \\
2-4(0,000) \\
3-4(0,000)\end{array}$} \\
\hline & $2(\mathrm{YYON})$ & $67,2 \pm 5,7$ & & \\
\hline & 3 (YNOY) & $67,9 \pm 5,5$ & & \\
\hline & $4(\mathrm{YNON})$ & $69,7 \pm 6,2$ & & \\
\hline \multirow{4}{*}{$\begin{array}{l}\text { Heigth } \\
(\mathrm{cm})\end{array}$} & 1 (YYOY) & $171,8 \pm 6,3$ & \multirow{4}{*}{0,000} & \multirow{4}{*}{$\begin{array}{l}1-4(0,000) \\
2-4(0,000) \\
3-4(0,000)\end{array}$} \\
\hline & $2(\mathrm{YYON})$ & $171,4 \pm 6,53$ & & \\
\hline & 3 (YNOY) & $170,6 \pm 6,5$ & & \\
\hline & $4(\mathrm{YNON})$ & $167,9 \pm 6,1$ & & \\
\hline \multirow{4}{*}{$\begin{array}{l}\text { Weigth } \\
\text { (kg) }\end{array}$} & 1 (YYOY) & $78,0 \pm 9,1$ & \multirow{4}{*}{0,000} & \multirow{4}{*}{$\begin{array}{l}2-4(0,000) \\
3-4(0,001)\end{array}$} \\
\hline & $2(\mathrm{YYON})$ & $78,4 \pm 11,03$ & & \\
\hline & 3 (YNOY) & $79,3 \pm 10,1$ & & \\
\hline & $4(\mathrm{YNON})$ & $75,2 \pm 11,1$ & & \\
\hline \multirow{4}{*}{$\begin{array}{c}\text { Chair Stand Test } \\
\text { (reps) }\end{array}$} & 1 (YYOY) & $16,6 \pm 3,1$ & \multirow{4}{*}{0,000} & $1-2(0,000)$ \\
\hline & $2(\mathrm{YYON})$ & $15,0 \pm 3,1$ & & $\begin{array}{l}1-3(0,015) \\
1-4(0,000)\end{array}$ \\
\hline & 3 (YNOY) & $15,3 \pm 2,9$ & & $\begin{array}{l}1-4(0,000) \\
2-4(0,000)\end{array}$ \\
\hline & $4(\mathrm{YNON})$ & $13,9 \pm 3,2$ & & $3-4(0,000)$ \\
\hline \multirow{4}{*}{$\begin{array}{l}\text { Arm-Crul Test } \\
\quad \text { (reps) }\end{array}$} & 1 (YYOY) & $18,0 \pm 2,4$ & \multirow{4}{*}{0,000} & $1-2(0,002)$ \\
\hline & $2(\mathrm{YYON})$ & $16,7 \pm 2,8$ & & $\begin{array}{l}1-4(0,000) \\
2-3(0,003)\end{array}$ \\
\hline & 3 (YNOY) & $17,8 \pm 2,2$ & & $\begin{array}{l}2-3(0,005) \\
2-4(0,000)\end{array}$ \\
\hline & $4(\mathrm{YNON})$ & $15,64 \pm 2,9$ & & $3-4(0,000)$ \\
\hline \multirow{4}{*}{$\begin{array}{c}\text { Two Minute Step Test } \\
\text { (steps) }\end{array}$} & 1 (YYOY) & $80,9 \pm 16,2$ & \multirow{4}{*}{0,000} & $1-2(0,000)$ \\
\hline & $2(\mathrm{YYON})$ & $67,7 \pm 16,1$ & & $1-3(0,000)$ \\
\hline & 3 (YNOY) & $80,7 \pm 15,7$ & & $\begin{array}{l}2-3(0,000) \\
2-4(0,000)\end{array}$ \\
\hline & $4(\mathrm{YNON})$ & $62,4 \pm 16,3$ & & $3-4(0,000)$ \\
\hline \multirow{4}{*}{$\begin{array}{l}\text { Chair Sit And Rich Test } \\
\qquad(\mathrm{cm})\end{array}$} & 1 (YYOY) & $-1,6 \pm 9,1$ & \multirow{4}{*}{0,000} & \\
\hline & $2(\mathrm{YYON})$ & $-4,9 \pm 8,7$ & & $1-3(0,002)$ \\
\hline & 3 (YNOY) & $-2,1 \pm 9,7$ & & $2-3(0,015)$ \\
\hline & $4(\mathrm{YNON})$ & $-5,3 \pm 8,5$ & & \\
\hline \multirow{4}{*}{ Back Scratch Test } & 1 (YYOY) & $-3,7 \pm 8,7$ & \multirow{4}{*}{0,006} & $1-2(0,001)$ \\
\hline & $2(\mathrm{YYON})$ & $-8,1 \pm 8,9$ & & $1-3(0,003)$ \\
\hline & 3 (YNOY) & $-8,1 \pm 10,1$ & & $\begin{array}{l}1-4(0,000) \\
2-4(0,000)\end{array}$ \\
\hline & $4(\mathrm{YNON})$ & $-11,3 \pm 9,6$ & & $3-4(0,004)$ \\
\hline \multirow{4}{*}{$\begin{array}{c}\text { 8-Foot Up-\&-Go Test } \\
\text { (seconds) }\end{array}$} & 1 (YYOY) & $4,9 \pm 1,2$ & \multirow{4}{*}{0,000} & \multirow{4}{*}{$\begin{array}{l}1-2(0,035) \\
1-4(0,000) \\
2-4(0,000) \\
3-4(0,000)\end{array}$} \\
\hline & $2(\mathrm{YYON})$ & $5,3 \pm 1,2$ & & \\
\hline & 3 (YNOY) & $5,0 \pm 0,9$ & & \\
\hline & $4(\mathrm{YNON})$ & $5,8 \pm 1,5$ & & \\
\hline
\end{tabular}

*p<0,05; **p<0,01; 1(YYOY): youth and now doing sports, 2(YYON):He did sports his youth, but now he doesn't, 3(YNOY): His youth didn't do sports but now he does, 4(YNON): he never did.

In the statistical evaluation; findings of the differences between the physical conditions of the participants and their sporting conditions according to the results of the motoric performance test were determined.

\section{Discussion}

Aging is a normal process for each individual during life whether human or not. Spending this process at the best possible level in terms of physical activity will improve the quality of life of the individual.

In the study, the frequency and percentage of the participants' occupation, educational status and income levels are given in table 1 . As a result of the analysis, the majority of the participants (87\%) were farmers, officer, workers and civil servants; they were found to have primary school level of education in general $(50 \%)$ and a large proportion $(62 \%)$ recieved a mid-range income level. Our participants have a similar view to the occupation and income distribution of our country (Ercan, 2011). 
Table 2 presents the findings of the participants regarding the level of sport they did in their youth and currently. It was determined that $29.1 \%$ of the participants did sports in their youth (26.7\% amateur, $2.4 \%$ professional level) and $70.9 \%$ did not. While $17.7 \%$ of the participants are currently doing sports, $82.3 \%$ of them are not doing sports anymore.

It was determined that the participants who were engaged in sports in their youth years were mostly interested in football (14.4\%), while the participants who currently do sports mostly do walking (17.1\%) (Table 3). It is observed that $32.2 \%$ of the participants who do not do sports at the moment used their old age as an excuse for not doing sports. $13.9 \%$ of them consider sport to be unnecessary, $10.5 \%$ of them used their illnesses as an excuse for not doing sports and $9.5 \%$ of them put forward shortage of time as an excuse for not doing sports. $70.9 \%$ of the participants said that they did not do sports in their youth and $82.3 \%$ of them said that they are not doing sports at the moment.

The physical condition of the participants and their motoric performance test results were examined according to their sporting status (YYOY, YYON, YNOY, YNON) in 4 categories (Table 4-5). At the end of the examination, it was found that the group that did not do sports in their youth years and are not currently doing it, were shorter and weaker (p $<0.05)$. Considering age-related geriatric syndromes, older people may be expected to be shorter and weaker due to malnutrition (Keskinler, Tufan and Oğuz, 2013).

The differences between the groups of Chair Stand Test results were found to be statistically significant $(\mathrm{p}<0.05)$. The LSD test was used to determine which groups had significant differences; The participants who did sport in their youth (YNON) and are currently doing it were found to have a higher test score than all the other groups and both the participants who did sports in their youth but who are not currently doing sports and the participants who did not do sports in their youth but who are currently doing sports (YNOY) had a higher test score than the participants who have not done any sport in their lives (YNON) $(\mathrm{p}<0.05)$.

The differences between Arm-Curl Test results of the groups were found to be statistically significant $(p<0.05)$. LSD test result; the participants who have done sports in their youth and are currently doing it have a higher test score than the ones who did sports in their youth but who are not currently doing it (YYON) and who have not done any sport in their lives; While the participants who did sports in their youth but who are not doing it now have a lower test score than the participants who did not do sports in their youth, participants who are currently doing sports (YNOY) have a higher test score than the participants who have not done any sports in their lives (YNON). The participants who did not do sports in their youth but who are doing it now (YNOY) were found to have a higher test score than the participants who have not done any sport in their lives (YNON).

The differences between the Two Minute Test results of the groups were found to be statistically significant ( $\mathrm{p}<0.05)$. LSD test result; The participants who did sports in their youth and who are currently doing sports (YYOY) were found to have a higher test score than the ones who did sports in their youth but are not currently doing it (YYON) and who did not do sports in their youth but who are currently engaged in sports (YNOY); The participants who did sports in their youth but do not do it now have a lower test score than the participants who did not do sports in their youth. The participants who are currently doing sports (YNOY) but who did not do any sports in their youth (YNON) have a higher test score than the participants who have never done any sport in their lives; the participants who did not do sports in their youth but who are doing it now (YNOY) were found to have a higher test score than the participants who have never done any sport in their lives (YNON).

The differences between the groups' Sit And Reach Chair Test results were found to be statistically significant ( $\mathrm{p}$ $<0.05$ ).LSD test result; The participants who did sports in their youth and are still involved in sport (YYOY) were found to have a higher test score than the ones who did sports in their youth but are not currently doing any (YYON) and those who did not do sports in their youth but who are currently engaged in sports (YNOY); The participants who did sports in their youth but who are not doing it currently have a higher test score than the participants who did not do sports in their youth but who are doing sports currently (YNOY) whereas they have a higher test score than the participants who have never done any sport in their lives; (YNON); the participants who did not do sports in their youth but who are doing it currently (YNOY) were found to have a higher test score than the participants who have not done any sport in their lives (YNON).

The differences between the groups' Back Scratch Test results were found to be statistically significant $(\mathrm{p}<0.05)$. LSD test result; the participants who did sports in their youth years and who are currently doing sports (YYOY) have a higher test score than all other participants; the participants who did sports in their youth but not currently doing it (YYON) and those who did not do sports in their youth but who do sports at the moment (YNOY) were found to have a higher test score than the participants who have not done any sports in their lives (YNON) $p<0.05$.

The differences between the 8 Foot Up-And-Go Test results of the groups were found to be statistically significant ( $p$ $<0.05$ ).LSD test result; participants (YYOY) who did sports in their youth and are currently doing it have a higher test score than the ones who did sports in their youth but who are not currently doing it (YYON) and who have never played 
any sport in their lives (YNON); The participants who did sports in their youth but are not currently doing it (YYON) and who did not do sports in their youth but who are currently engaged in sports (YNOY) were found to have a higher test score than the ones who have not done any sport in their lives $(\mathrm{p}<0.05)$.

In the study which examined the effect of sporting activities on motor skills in youth, it has been determined that individuals who have done sport in every point of their lives have better sportive skills than individuals who have done sports or have not done any sport at any time in their lives. Considering that individuals who have been involved in sports at every stage of their lives move more than others, it is to be expected that the basic motor characteristics such as force, speed, durability, quickness, flexibility and balance will be in better condition. In the study, it was found that individuals who did sports at a certain time of their youth but who are not currently doing well have better condition in all motor skills than individuals who are not interested in any sporting activity throughout their lives. The high frequency or duration of training or physical activity has a positive effect on physical and physiological compliance (Bompa, 2007).

Also in the study; It was determined that individuals who did not do sports in their youth but who started to do sports in their old age had better motor skills than those who did sports in their youth but then left the sport. This can be explained by the detraining effects. Supporting our study, Stergios et al. (2018) in their study with 12 football players in the 19-24 age group, found that at the end of the 4-week transition period of non-training players, body weight, body mass index and a significant increase in speed was determined. Alvero et al. (2017), included 43 players and 10 sedentary in their study. The players' 6-week detraining period has been reported to show a significant increase. Theodorou et al. (2016), tested 56 patients with coronary artery disease and in their research control, strength, endurance and combined (strength and endurance) group were divided into 4 groups. Participants were included in an 8-month training program which was suitable for their training group and it was found that there were positive developments in 3 exercise groups at the end of the program. However, after 8 months, it was reported that the group that performed strength and endurance studies showed slower detraining effects. Fatouros et al. (2005) conducted research with a total of 52 participants with a mean age of 71,14 with control, 18 with a low density and 20 with a high intensity group, followed by a 24-week training period following a 48 -week detraining period. They reported that they had more training gains and lost more gains in a longer period of time. In another study, Fatouros et al. (2004), studied 65-year-olds and included over 19 participants in their study, 16-week endurance training was effective against the problem of oxidative stress disorder, but at the end of 4-month detraining season, an increase in oxidative stress disorders and training effects have been found to be largely lost. Carvalho et al. (2007), in their study with 57 participants with an average age of 68 , reported that the majority of the gains at the end of the 8-month exercise program were lost at the end of the 3-month detraining season. Harris et al. (2007), in their study with 61 participants with a mean age of 71 years, found that at the end of the 18-week exercise program strength and endurance capacity increased significantly, but due to the detraining at the end of the 6th and 20th weeks, the training effects decreased. Oliveira et al. (2017), study of 51 women with an average age of 68 at the end of their research found the results of 9 months of water and water exercises showed a fall in blood pressure and increased strength, endurance and agility values, 3-year detraining season again reported that the end of the old values. Lovell et al. (2010), 70-80 age group with 24 sedentary study, reported that at the end of a 16-week training period of the upper and lower extremities strength and power development had made significant progress, but at the end of a 4-week detraining period all neuromuscular parameters, reported a significant decline, though they were still high. The studies examined support the study in terms of the negative effects of the detraining phase.

\section{Conclusion}

In order to improve the quality of life in the elderly, it has been shown that physical exercises which are carried out in the youth period but that do not continue in old age are not as effective as life long participation in sport. In fact, continuing physical exercises in old age are effective tools. Therefore, It can be said that what you did yesterday and what you do today are both important, since regular physical activities during old age and practicable sportive exercises can improve the quality of life by reducing the number of physical, mental and psychological problems associated with old age. The exercises as related to term of sport and exercise have positive effects on physical fitness levels but if the sport does not become a part of ones lifestyle, all gains will be lost over time. Starting from this point of view, the expressions of "It doesn't matter what you did yesterday, what you're doing today is what matters" can also be said to relate to exercise and sport. 


\section{References}

Alvero, J. C., Ronconi, M., García, J. R., Carrillo, M. D. A. G., Jíménez, M. L., Correas, L. G., \& Álvarez, E. C. (2017). Body composition changes after sport detraining period. Nutricion hospitalaria, 34(3), 632-638. https://doi.org/10.20960/nh.618

Bird, M. L., \& Fell, J. (2014). Positive long-term effects of pilates exercise on the age-related decline in balance and strength in older, community-dwelling men and women. Journal of aging and physical activity, 22(3), 342-347. https://doi.org/10.1123/JAPA.2013-0006

Bompa, T. O. (2007). Training Theory and Method-Periodization[Antrenman Kuramı ve Yöntemi-Dönemleme]. Sports Bookstore, 3rd Edition, Ankara.

Brady, A. O., Straight, C. R., \& Evans, E. M. (2014). Body composition, muscle capacity, and physical function in oldera dults: an integrated conceptual model. Journal of aging and physical activity, 22(3), 441-452. https://doi.org/10.1123/JAPA.2013-0009

Bullo, V., Bergamin, M., Gobbo, S., Sieverdes, J. C., Zaccaria, M., Neunhaeuserer, D., \& Ermolao, A. (2015). The effects of Pilates exercise training on physical fitness and well being in the elderly: a systematic review for future exercise prescription. Preventive medicine, 75, 1-11. https://doi.org/10.1016/j.ypmed.2015.03.002

Carvalho, M. J., Marques, E., \& Mota, J. (2009). Training and detraining effects on functional fitness after a multicomponent training in older women. Gerontology, 55(1), 41-48. https://doi.org/10.1159/000140681

Ercan, H. (2011). Türkiye'de mesleki görünüm. Uluslararası Çalışma Örgütü. https://media.iskur.gov.tr/13497/turkiyede-mesleki-gorunum.pdf adresinden 24.10.2018 tarihinde alınd1.

Fatouros, I. G., Jamurtas, A. Z., Villiotou, V., Pouliopoulou, S., Fotinakis, P., Taxildaris, K., \& Deliconstantinos, G. (2004). Oxidative stress responses in older men during endurance training and detraining. Medicine \& Science in Sports \&Exercise, 36(12), 2065-2072. https://doi.org/10.1249/01.MSS.0000147632.17450.FF

Fatouros, I. G., Kambas, A., Katrabasas, I., Nikolaidis, K., Chatzinikolaou, A., Leontsini, D., \& Taxildaris, K. (2005). Strength training and detraining effects on muscular strength, anaerobic power, and mobility of inactive older men ar eintensity dependent. British Journal of Sports Medicine, 39(10), 776-780. https://doi.org/10.1136/bjsm.2005.019117

Gobbo, S., Bergamin, M., Sieverdes, J. C., Ermolao, A., \& Zaccaria, M. (2014). Effects of exercise on dual-task ability and balance in olderadults: a systematic review. Archives of gerontology and geriatrics, 58(2), 177-187. https://doi.org/10.1016/j.archger.2013.10.001

Harris, C., Debeliso, M., Adams, K. J., Irmischer, B. S., \& Gibson, T. A. S. (2007). Detraining in the older adult: effects of prior training intensity on strength retention. Journal of strength and conditioning research, $21(3), 813$. https://doi.org/10.1519/00124278-200708000-00027

Horníková, H., Doležajová, L., \& Zemková, E. (2018). Playing table tennis contributes to better agility performance in middle-aged and older subjects. Acta Gymnica, 48(1), 15-20. https://doi.org/10.5507/ag.2018.004

Jeon, Y., Shin, M., Kim, C., Lee, B. J., Kim, S., Chae, D., ... \& Kim, B. (2018). Effect of Squat Exercises on Lung Function in Elderly Women with Sarcopenia. Journal of clinical medicine, 7(7), 167. https://doi.org/10.3390/jcm7070167

Jeoung, B. J., \& Lee, Y. C. (2015). A Study of relationship between frailty and physical performance in elderly women. Journal of exercise rehabilitation, 11(4), 215-219. https://doi.org/10.12965/jer.150223

Keskinler, M. V., Tufan, F., \& Oğuz, A. (2013). Geriatrik Sendromlar. Okmeydanı Tıp Dergisi, 29(2), 41-48. https://doi.org/10.5222/otd.supp2.2013.041

Kim, H., Suzuki, T., Kim, M., Kojima, N., Yoshida, Y., Hirano, H., ... Yoshida, H. (2015). Incidence and predictors of sarcopenia onset in community-dwelling elderly Japanese women: 4-year follow-up study. Journal of the American Medical Directors Association, 16(1), 85.e1-8. https://doi.org/10.1016/j.jamda.2014.10.006

Leach, S. J., \& Ruckert, E. A. (2016). Neurologic changes with aging, physical activity, and sport participation. Topics in Geriatric Rehabilitation, 32(1), 24-33. https://doi.org/10.1097/TGR.0000000000000088

Lovell, D. I., Cuneo, R., \& Gass, G. C. (2010). The effect of strength training and short-term detraining on maximum force and the rate of force development of older men. Europeanjournal of applied physiology, 109(3), 429-435. https://doi.org/10.1007/s00421-010-1375-0

Mijnarends, D. M., Koster, A., Schols, J. M., Meijers, J. M., Halfens, R. J., Gudnason, V., ... Meirelles, O. (2016). 
Physical activity and incidence of sarcopenia: the population-based AGES-Reykjavik Study. Age and ageing, 45(5), 614-620. https://doi.org/10.1093/ageing/afw090

Oliveira, R., Santa-Marinha, C., Leão, R., Monteiro, D., Bento, T., Santos Rocha, R., \& Brito, J. P. (2017). Exercise training programs and detraining in older women Journal of Human Sportand Exercise. Journal of Human Sportand Exercise, 12(1), 142-155. https://doi.org/10.14198/jhse.2017.121.12

Rikli, R. E., \& Jones, J. C. (2001). Senior fitness test manual. Human Kinetics, Champaign, Illinois, 49-87

Santilli, V., Bernetti, A., Mangone, M., \&Paoloni, M. (2014). Clinicaldefinition of sarcopenia. Clinicalcases in mineral and bone metabolism, 11(3), 177-180. https://doi.org/10.11138/ccmbm/2014.11.3.177

Stergios, K., Maria, G., Zacharoula, P., Georgios, K., Athanasios, D., \& Evangelos, B. (2018). Detraining effects of the transition period on endurance and speed-related performance parameters of amateur soccer players. International Journal of Scientific Research, 7(2), 40-42.

Theodorou, A. A., Panayiotou, G., Volaklis, K. A., Douda, H. T., Paschalis, V., Nikolaidis, M. G., ... Tokmakidis, S. P. (2016). Aerobic, resistance and combined training and detraining on body composition, muscle strength, lipid profile and inflammation in coronary artery disease patients. Research in Sports Medicine, 24(3), 171-184. https://doi.org/10.1080/15438627.2016.1191488

Yüksek, S. (2017). The Effects of Performing Prayer on the Physical Fitness Levels of Men Over 60 Years Old. Journal of Education and Training Studies, 5(11), 56-63. https://doi.org/10.11114/jets.v5i11.2641

\section{Copyrights}

Copyright for this article is retained by the author(s), with first publication rights granted to the journal.

This is an open-access article distributed under the terms and conditions of the Creative Commons Attribution license which permits unrestricted use, distribution, and reproduction in any medium, provided the original work is properly cited. 